\title{
FEMINISMO NEGRO E PENSAMENTO INTERSECCIONAL: CONTRIBUIÇÕES PARA AS PESQUISAS DAS CULTURAS INFANTIS
}

\author{
Flavio Santiago ${ }^{1}$ \\ Ana Lúcia Goulart de Faria ${ }^{2,3}$
}

\begin{abstract}
RESUMO: O presente artigo tem por objetivo, a partir do pensamento feminista negro, contribuir com os estudos da produção das culturas infantis, referentes à participação das crianças desde a pequena infância na construção da realidade social, trazendo para a cena as crianças com idade entre 0 a 3 anos, do coletivo infantil de uma creche pública, e as suas reinterpretações a respeito das intersecções entre as práticas racistas e sexistas. Traremos para discussão as crianças pequenininhas, negras e brancas, suas resistências e suas transgressões, que tensionam as hierarquias patriarcais e racistas. Construindo outros modos de se viver no mundo, por meio de suas brincadeiras, elas lançam outros olhares para as relações vigentes na sociedade e desafiam o poder adultocêntrico que pretende calá-las.
\end{abstract}

Palavras-chave: Feminismo Negro. Racismo. Culturas infantis. Creche. Crianças pequenininhas.

\section{BLACK FEMINISM AND INTERSECTIONAL THOUGHT: CONTRIBUTIONS TO PEER CULTURES RESEARCH}

\begin{abstract}
The purpose of this article is, based on the black feminist thought, to contribute to the studies on the production of peer cultures, regarding the participation of children since early childhood in the construction of social reality, bringing to the scene children aged 0 to 3 from the child collective of a public ECEC (early childhood education and care) and their reinterpretations towards the intersections between racist and sexist practices. We will bring to discussion the tiny young children, black and white, their resistance and transgressions, which tension the patriarchal and racist hierarchies. By building other ways of living in the world, through their games, they cast other perspectives at the relationships in force in society and defy the adult-centric power that intends to silence them.
\end{abstract}

Keywords: Black Feminism. Racism. Peer cultures. ECEC. Tiny young children.

Este estudo foi apoiado financeiramente pela Fundação de Apoio à Pesquisa do Estado de São Paulo (FAPESP)/CAPES, pelo fomento ao processo n. 15/02464-0. Como resultado da pesquisa, temos a tese Eu quero ser o sol!: (re) interpretações das intersecções entre as relações raciais e de gênero nas culturas infantis entre as crianças de 0 a 3 anos em creche, escrita por Flávio Santiago, disponível em: http://repositorio.unicamp.br/handle/REPOSIP/347293

1.Universidade de São Paulo - Faculdade de Educação - São Paulo (SP), Brasil. E-mail: santiagoflavio2206@gmail.com

2.Universidade Estadual de Campinas - Faculdade de Educação - Campinas (SP), Brasil. E-mail: cripeq@unicamp.br

3.Università Degli Studi Milano Bicocca - Faculdade de Ciência da Formação - Milão, Itália. E-mail: ana.goulart@unimib.it

Editor de Seção: Luana Costa Almeida 


\title{
FEMINISMO NEGRO E PENSAMIENTO INTERSECCIONAL: CONTRIBUCIONES PARA LA INVESTIGACIÓN CON CULTURAS INFANTILES
}

\begin{abstract}
RESUMEN: El propósito de este artículo es, basado en el pensamiento feminista negro, contribuir a los estudios de la producción de culturas infantiles, refiriéndose a la participación de niños y niñas desde la primera infancia en la construcción de la realidad social, llevando a la escena a niños y niñas de 0 a 3 años del colectivo infantil de una escuela infantil pública y sus reinterpretaciones sobre las intersecciones entre las prácticas racistas y sexistas. Traeremos a discusión a los niños chiquititos y niñas chiquititas, blancos y negros, su resistencia y transgresiones, que tensan las jerarquías patriarcales y racistas. Al construir otras formas de vivir en el mundo, a través de sus juegos, lanzan otra mirada sobre las relaciones vigentes en la sociedad y desafían el poder adultocéntrico que intenta silenciarlos.
\end{abstract}

Palabras clave: Feminismo Negro. Racismo. Culturas infantiles. Centros infantile. Niños y niñas chiquititos(as).

\section{Introdução}

$\mathrm{E}$

ste artigo busca contribuir, a partir do Feminismo Negro, com os estudos das culturas infantis, explorando os aspectos relativos às (re)interpretações das crianças pequenininhas, negras e brancas, de 0 a 3 anos, de um coletivo infantil, em uma creche pública da região metropolitana de Campinas (SP), acerca das intersecções das práticas racistas e sexistas. Os dados aqui apresentados foram coletados durante a realização de uma pesquisa etnográfica, em que o pesquisador esteve junto às crianças pequenininhas, brancas e negras, durante um ano, indo quatro vezes no período da manhã e uma vez no período da tarde.

O fazer etnográfico exige um estado de alerta constante no tocante a metodologias relativas ao controle, sendo sempre necessário nos recordarmos da máxima de estranhar o familiar e familiarizar-se com o estranho (VELHO, 1978), de modo a experienciar diferentes encontros no campo de pesquisa. Nem sempre o estar em campo se faz de modo tranquilo; vivemos intensamente as inconstâncias presentes em quaisquer relações existentes na sociedade; o processo de estranhamento do familiar demora tempo e exige leituras teóricas e disposição para perceber movimentos, gestos e relações de afeto de vários tipos, antes naturalizados.

Nossa argumentação adotará os seguintes caminhos: traremos à cena as crianças pequenininhas, negras e brancas, e suas resistências. Buscaremos compreender de que modo as meninas pequenininhas e os meninos pequenininhos percebem, reinventam e reinterpretam a intersecção entre as práticas racistas e as práticas sexistas. Para tal análise, partiremos da perspectiva do Feminismo Negro, destacando suas indagações e contribuições para o campo da educação, em especial para a educação infantil, primeira etapa da educação básica. Por meio dos estudos de feministas negras, pretendemos demonstrar a importância de se pensar uma articulação entre os marcadores sociais de diferença raça e gênero, com as mulheres negras como as principais protagonistas que alavancam tal discussão, seja no campo acadêmico, seja na luta social por equidade ${ }^{1}$.

Os dados nos quais nossas reflexões se baseiam resultam de uma pesquisa etnográfica realizada em uma creche pública da região metropolitana de Campinas (SP), com um coletivo de crianças 
pequenininhas de 0 a 3 anos. É importante destacar que "a escolha por uma denominação específica como 'pequenininhas' para estas crianças não pretende ocultar seu lugar no diminutivo, pelo contrário, busca demarcara sua existência naquilo que são e na grandeza do que representam" (PRADO, 1999, p. 111). Independente de nossa idade cronológica, construímos relação para com um mundo, somos atores e atrizes sociais desde o primeiro choro, modificando as relações ao nosso entorno. "Consideramos os bebês como cidadãos(ãs) de pouca idade (cf. BENJAMIN, 1984), crianças pequenininhas, não como uma categoria à parte, mas como integrantes do que denominamos crianças e da categoria infância" (MACEDO, 2016, p. 12) ${ }^{2}$. A pesquisa com crianças pequenininhas se caracteriza como um grande desafio, pois não basta se sentar com as crianças no chão e brincar; é necessário ser aceito(a), criar caminhos de aproximação e compreender outras linguagens, sentir e falar. Convém frisar a relevância das pesquisas com crianças negras e educação para as infâncias em nosso país, uma vez que os estudos que trazem como foco as crianças negras, muitas vezes, ainda recaem em uma perspectiva hegemônica ao analisar as experiências, tanto no viés da pesquisa educacional quanto no cotidiano das creches e pré-escolas, nas quais as crianças negras estão em maior número (GOMES, 2019).

Quando realizamos pesquisa sobre as culturas infantis, é fundamental mantermos alerta nossos olhos e ouvidos já adultos: em muitos momentos eles não nos permitem captar com maestria aquilo que os meninos e as meninas fazem concretamente (SANTIAGO, 2019a); às vezes, podemos interpretar de modo adultocêntrico ${ }^{3}$ um abraço, caindo na armadilha de interpretar a infância "em período temporal de incapacidade generalizada e/ou de preparo para a aquisição de capacidades por vir [...]" (MIGUEL, 2015, p. 39). Paralelamente a esse aspecto, também temos de estar atentos ao nosso local de fala, pois tudo o que escrevemos e observamos está inserido no contexto histórico e num lugar singular; o que escrevemos está situado, posicionado. Nesse sentido, nosso local de fala neste artigo é de pessoas brancas comprometidas com a luta antirracista.

Este artigo não pertence ao campo epistemológico do Feminismo Negro, pois, como argumenta Collins (1990), viver a vida como uma mulher negra é pré-requisito para produzir o pensamento feminista negro. Assim, somos aliados às principais agendas políticas reivindicadas pelas mulheres negras, o que inclui também uma autocrítica constante do nosso lugar como pesquisador branco e pesquisadora branca, bem como um reconhecimento de nossos privilégios no contexto estruturante das relações raciais. Quando destacamos os pontos de partida das interpretações ao longo do artigo, não estamos nos referindo somente às experiências individuais, mas procurando entender o lugar social de onde falamos, localizando-nos nas redes de poder, as quais interferem diretamente nas experiências do mundo, bem como no reconhecimento da humanidade das pessoas (RIBEIRO, 2017).

Para cumprir tal intento, o artigo está organizado da seguinte maneira: inicialmente, serão apresentadas algumas inquietações propostas pelo Feminismo Negro e, posteriormente, traremos fragmentos do diário de campo da pesquisa de Santiago (2019a), também autor deste artigo. Analisaremos os fragmentos desse caderno de campo a partir das críticas e dos esforços realizados e expressos no pensamento das feministas negras, no intuito de evidenciar a necessidade de se pensar para além de uma ideia abstrata de relações de gênero. Destacaremos, também, as reverberações das mazelas postas pelos sistemas de opressão na infância. O Feminismo Negro, como destaca Pereira, "é um grande aliado para o entendimento das opressões e silenciamentos que tanto a menina/mulher negra quanto o menino/homem negro sofrem na sociedade" (2020, p. 94-95). Na sequência, traremos para discussão a importância de se ater também ao protagonismo infantil, tomando as crianças pequenininhas como atrizes sociais, as quais redesenham e resistem às formas de imposição e predeterminações estabelecidas pelos estereótipos de gênero e raça. 


\section{Feminismo Negro: Rompendo com o Legado Eurocêntrico}

O conceito de Feminismo Negro vem sendo desenvolvido por mulheres negras ativistas há mais de um século; as resistências, seja pelos abortos dos filhos frutos dos estupros dos senhores, seja pela militância acadêmica, atualmente são exemplo desse movimento. O ponto de vista das mulheres negras desafia o que é normalmente tomado como verdade e, ao mesmo tempo, questiona o processo por meio do qual as Ciências Sociais vêm sendo produzidas há anos.

A singularidade da condição racial da mulher negra e a categoria raça serviram no momento inicial como moeda simbólica para, frente às feministas "brancas", criar a diferenciação moeda da condição mulher (gênero) como instrumento de questionamento ao movimento negro a respeito das posições secundárias assumidas e impostas às lideranças femininas no seio das entidades dos vários segmentos do movimento negro (MOREIRA, 2011, p. 116-117).

O Feminismo Negro, a partir das décadas de 1970 e 1980, tem sua expressão mais acentuada com a produção intelectual de feministas negras, a exemplo, no Brasil, de Lélia Gonzalez (1983). Essas produções denunciam a invisibilidade das mulheres negras no feminismo, rompendo com a ideia de uma mulher genérica, construída pelo próprio legado do sexismo e do patriarcado ocidental - e "isso acontecia devido ao fato de não se identificarem com um movimento branco e de classe média, e pela falta de empatia em perceber que mulheres negras possuem pontos de partida diferentes [...]" (RIBEIRO, 2018, p. 74). Assim, as feministas negras nos alertam em relação a assumir posições que parecem representações da totalidade, pois essas acabam por reproduzir inúmeras vezes epistemologias que policiam qualquer posição que se desvie da experiência oficial do que seja mulher, branca, cis, heterossexual. O racismo e sexismo se combinam e criam barreiras nocivas entre as mulheres (hooks, 2018). As mulheres negras, ao questionarem a lógica de pensamento até então legitimada dentro do feminismo branco, cisgênico e eurocentrado, revolucionaram o modo com o qual o próprio movimento construía sua agenda política e compartilhava suas experiências no que tange a ser mulher e às suas lutas pela desconstrução do patriarcado e do machismo.

O Feminismo Negro é um campo epistemológico e político que pode ser vinculado ao espaço da negritude, não apenas desafiando as formas de dominação de uma sociedade tradicionalmente branca e masculina, como também colocando em tensionamento a produção de conhecimento desse grupo (WESCHENFELDER; FABRIS, 2019). De acordo com Carneiro (2011), as mulheres negras se constituem e lutam em duas frentes: uma de "enegrecer" a agenda do movimento feminista; e outra de "sexualizar" as pautas do movimento social de negras e negros, trazendo olhares para as diferenças nas discussões e nas práticas políticas desses segmentos. Cria-se, assim, uma dupla percepção, tanto na afirmação de novos sujeitos políticos quanto na reivindicação de um reconhecimento da diversidade e das desigualdades existentes entre os sujeitos.

O feminismo traz uma contribuição importantíssima, do ponto de vista de uma visão de mundo. Mas as feministas também são formadas para desconhecer as desigualdades raciais. Formadas para pensar o Brasil como uma democracia racial. E aí, contraditoriamente, ainda que o movimento feminista consiga perceber em que nível a diferença de sexo é utilizada na reprodução das desigualdades, não consegue perceber como as diferenças raciais são trabalhadas na perspectiva da recriação constante dos mecanismos de discriminação racial (BAIRROS, 2008, s. p.). 
Nenhuma intervenção, conforme aponta hooks (2018), mudou mais a agenda política do feminismo do que reconhecer a realidade do racismo nas vidas das mulheres e meninas negras; enquanto apenas era priorizado o gênero, as mulheres brancas assumiam o palco das discussões e pautas, não havendo uma sororiedade entre as vivências e experiências. As hierarquias raciais também se faziam dentro do movimento.

No campo teórico, um dos desdobramentos das críticas trazidas pelas feministas negras, lésbicas e mulheres de países colonizados e colonizadores foi o desenvolvimento da teoria interseccional, que procura captar a complexidade da articulação entre gênero e outras diferenças sociais (FACCHINI, 2018). O feminismo tem contribuído para transformar a ciência, enriquecendo tanto a discussão da questão racial quanto a questão de gênero na sociedade brasileira (RIBEIRO, 2018). Como destaca Moreira, "a luta das mulheres negras é comprometida com o resgate das suas histórias, recriando em suas potencialidades a tentativa de buscar mudanças que permitam novas experiências relacionais de poder na sociedade” (2017, p. 12).

Uma das principais contribuições do Feminismo Negro foi questionar a visão eurocêntrica, ocidental e universal das mulheres, na qual o feminismo branco se fundamentava; isso não significa que os termos "mulher" e "menina” tenham deixado de ser úteis, porque é indispensável que sejam entendidos como conceitos que referenciam múltiplas vivências (KYRILLOS, 2020).

As experiências que marcam as histórias das meninas, brancas e negras, bem como meninos, negros e brancos, são distintas, existindo vivencias diferenciadas na estrutura hierárquica racista, sexista e de classe (SANTIAGO, 2019b). Nessa perspectiva, as diferenças entre brancos(as) e negros(as) não estão em suas essências, mas se apresentam como "[...] diferença de condições sociais" (BRAH, 2006, p. 341). Assim, no contexto de pensar as especificidades das infâncias, a perspectiva feminista negra, aponta Pereira, "traz na sua pauta de lutas a importância de se discutir essas questões que evoco, no sentido de desconstruir e derrubar padrões socialmente naturalizados, [...] que, na maioria das vezes, são sutis e que não reconhecemos" (2020, p. 95).

O conceito de interseccionalidade não tem sua origem "academicista" no Brasil, mas nos Estados Unidos, e ganhou popularidade na Conferência Mundial contra Racismo, Discriminação Racial, Xenofobia e Formas Conexas de Intolerância, em Durban, na África do Sul, em 2001. Crenshaw (2002) foi uma de suas criadoras e afirma que as intersecções entre raça e gênero contribuem de maneira efetiva para estruturar a vida de mulheres negras e homens negros, sobretudo pelas práticas racistas e sexistas. A autora também destaca que o machismo e o racismo não são os únicos marcadores sociais de diferença que podem ser pautados em uma discussão interseccional. Ademais, pode-se afirmar que esse conceito “[...] é uma sensibilidade analítica, pensada por feministas negras, cujas experiências e reivindicações intelectuais eram inobservadas tanto pelo feminismo branco quanto pelo movimento antirracista, a rigor, focado nos homens negros" (AKOTIRENE, 2018, p. 13).

De acordo com esses pressupostos, a perspectiva da interseccionalidade, na medida em que captura "[...] as consequências estruturais e dinâmicas da interação entre dois ou mais eixos de subordinação" (CRENSHAW, 2002, p. 177), é indispensável à análise das hierarquias produzidas e reproduzidas nas diferentes esferas da vida social, inclusive quando pensamos as culturas infantis, pois as relações construídas refletem problemas oriundos da inter-relação de diferentes categorias; as crianças, desde que nascem, estão inseridas na sociedade (SANTIAGO, 2020). Assim, a interseccionalidade, como aponta Akotirene (2018), visa dar instrumentalidade teórico-metodológica à inseparabilidade estrutural de racismo, capitalismo e "cisheteropatriarcado", permitindo-nos enxergar a colisão das estruturas, a interação simultânea das opressões, além do fracasso do feminismo branco eurocentrado no sentido de contemplar as mulheres negras.

As mulheres negras, quando reivindicaram uma nova forma de se olhar para as relações de gênero, ensinaram que as opressões estabelecidas pelos sistemas sexistas e patriarcais não são elementos que devem 
ser pensados de modo isolado - a vida não se faz apenas por meio de uma faceta social. Os marcadores, como classe, raça e idade, também influenciam diretamente as vivências e os modos pelos quais os sujeitos estabelecem sua relação na sociedade, tornando fundamental pensarmos o contexto social de um modo interseccional. “As feministas negras brasileiras, então, inauguram no país um debate em que é possível [...] articular distintas formas de dominação e posições de desigualdade acionadas nos discursos regulatórios" (OLIVEIRA, 2018, p, 35).

A interseccionalidade, como destaca Santiago, visa destacar como "as relações historicamente contingentes e específicas a determinada conjuntura constroem modos de vida e legitimam processos de hierarquização" (2019a, p. 6); desse modo, "não se pode explicar o racismo abstraindo-o das outras relações sociais” (MELLINO, 2019, p. 117). Em especial, neste artigo, o olhar feminista negro nos forneceu aportes para problematizar e questionar algumas ações docentes e brincadeiras das crianças pequenininhas observadas durante o trabalho de campo, possibilitando-nos fazer interpretações dos dados obtidos por meio de novas lentes, que favorecessem pensar os processos de intersecção e suas correlações históricas.

\section{As Crianças Pequenininhas Rabiscam as Fronteiras das Práticas Racistas e Sexistas}

As crianças pequenininhas não são apenas produzidas pelas culturas; também são produtoras de cultura. As diferenças entre os meninos pequenininhos e as meninas pequenininhas e entre elas e eles e os(as) adultos(as) não são quantitativas, mas qualitativas: a criança não sabe menos, sabe outras coisas (COHN, 2005). As crianças, quando brincam com os brinquedos ou de faz de conta, experimentam e representam papéis que estão para além das convenções sociais e determinações de gênero. Por isso, é preciso que as instituições de educação infantil compreendam o potencial transformador e transgressor das crianças, permitindo-lhes manifestarem suas linguagens nos diferentes tempos e espaços de convívio e interação (SAYÃO, 2016).

Fernandes (2004) realizou uma pesquisa pioneira no Brasil a respeito das culturas infantis, no bairro do Bom Retiro, em São Paulo, na década de 1940. Em sua pesquisa, o sociólogo afirma que as crianças não apenas imitam, mas também modificam a sociedade por meio da cultura infantil. No âmago da experiência direta e concreta, elas compreendem "como agir em cada circunstância, na qualidade de parceiro e membro de dado agrupamento social há um tempo" (FERNANDES, 2004, p. 207). É importante destacar que Florestan Fernandes utilizou o conceito de cultura infantil no singular, o que reflete o contexto sociocultural da época e uma escolha teórica que generaliza a dimensão simbólica da infância. Entretanto, nós, autor e coautora deste artigo, partimos dos estudos da Pedagogia da Infância, na interface com as Ciências Sociais. Portanto, utilizamos o conceito de cultura infantil no plural, para demarcar a existência de diferentes infâncias e a pluralidade de experiências no fazer das crianças quando estão juntas. Pensar uma infância universal e genérica é um equívoco; como bem apontam as feministas negras, toda generalização é uma forma de dominação, encobrindo uma realidade sócio-histórica ${ }^{4}$.

Santiago (2019a) destaca, em sua tese de doutorado, que, em um dia, no início da primavera de 2016, todos(as) na turma (incluindo as docentes e ele, pesquisador) se animaram para brincar no espaço externo, de modo a poder também pegar um pouco do sol da manhã. Uma das docentes propôs levar um fogãozinho e algumas panelinhas para as crianças pequenininhas brincarem. A ideia não era criar uma brincadeira específica, mas deixar que elas construíssem as próprias relações com aqueles objetos. Nesse dia, os meninos pequenininhos, negros e brancos, assumiram o comando da brincadeira; só posteriormente as meninas pequenininhas, negras e brancas, foram convidadas por eles para participar. 
Inquieto com a forma com que estruturaram a brincadeira, Santiago resolveu se aproximar e perguntar: "O que vocês estão fazendo de gostoso? Eu posso comer?" (2019a, p. 68). Imediatamente, um menino pequenininho branco respondeu: "Estamos fazendo comida da força! Comida pra trabalhar! Você não pode comer! É pra Afy, Baina e Dofi ${ }^{5}$, elas vão trabalhar!” Após essa afirmação, o pesquisador ficou na dúvida do que era considerado trabalho e perguntou: "Mas eu também vou trabalhar, não trabalho?" Sem hesitar, o menino pequenininho branco respondeu: "Não, você fica aqui brincando com a gente! Elas vão trabalhar em outro lugar..." (SANTIAGO, 2019a, p. 68). Depois dessa resposta, as crianças pequenininhas voltaram a brincar entre elas e não permitiram que o pesquisador continuasse a participar da brincadeira.

Na busca por conhecer e reconhecer as relações de gênero entre meninas e meninos na educação infantil, é fundamental observar a criançada e suas criações (GOBBI, 2015, p. 159). Isso requer construir uma escuta autêntica, que busque observar não as ideias pré-concebidas a respeito da infância ou os projetos sociais que meninos e meninas desempenham na sociedade, mas os modos capazes de perceber as crianças nos seus próprios pensamentos (SOCI, 2015). No caso descrito anteriormente, nota-se a ironia dos meninos na inversão dos papéis de gênero tradicionais, em que o homem come a força, pois vai trabalhar fora de casa. Ali, eram as meninas que iam trabalhar. O pesquisador ficaria brincando com os meninos sem comer.

Nem tudo do universo adulto tem o mesmo sentido para as crianças pequenininhas, por isso é fundamental estarmos atentos e não deixarmos que nossos estereótipos limitem a experienciação do mundo de meninos e meninas. As crianças pequenininhas nos mostram que há inúmeras possibilidades de existir e construir as infâncias, bem como de vivenciar as relações de gênero:

[...] quando a gente estava fazendo ensaio da música da sementinha, quando eu levei a música para as crianças, eu propus, eu falei: "vamos fazer uma representação dessa música com as crianças, corporalmente vamos representar a música?" E aí que eu sugeri confeccionar as nuvens e fazer o sol. E aí, todas as vezes que a gente brincava com a música, que eu falo que era uma brincadeira, não tinha personagens fixos, mas a Layla [menina negra pequenininha], ela sempre pediu "deixa eu ser o sol?" Eu achei o máximo assim, né, “deixa eu ser?” E aí ela foi muito enfática, porque na realidade as crianças querem ser as coisas porque elas querem experimentar os papéis, e ela foi muito enfática, porque eu acho que ela sempre foi o sol, eu acho que o sol foi o único elemento que não teve rotatividade de crianças, "deixa, eu quero ser", e ela pedia muito. "Então, tá bom, vai lá ser o sol, vai falar para a Dacia te dar o sol." Zarina, docente branca, informação verbal (SANTIAGO, 2019a, p. 85).

Layla quer ser o sol, brilhar! Transcende o processo de racialização, que marca a subjetividade das meninas negras com elementos do racismo e sexismo, durante o ensaio e a apresentação da peça. Ela pode ser a responsável por fazer as flores crescerem durante a primavera, tomando em suas mãos a produção da vida. Como destaca Silva (1998), as mulheres negras querem deixar de ser apenas estatísticas e ter o protagonismo na vida, ser representadas; querem se fazer ver e conhecer tal como são. As meninas pequenininhas negras querem ser, almejam ter o protagonismo, de tal modo como têm apontado historicamente as feministas negras em relação às mulheres negras na construção da história e da sociedade.

Assim como Layla (menina negra pequenininha), outras meninas pequenininhas, em diferentes momentos na pesquisa de Santiago (2019a), produziram formas de experimentação do seu protagonismo e criaram formas de organização da vida. Como exemplo, também temos a cena em que Chioma (menina negra pequenininha) e Dalila (menina branca pequenininha) decidem levar os cavalos para passear, em um ato de amizade e ruptura com a ideia de feminilidade ligada à maternagem, expressa muitas vezes pelo cuidado com as bonecas. Como aponta Santiago (2019a), as meninas pequenininhas não apenas empurravam os cavalos, 
mas também se tornaram líderes de um pequeno rebanho de três animais; com eles, Chioma e Dalila subiam os morros da creche e guerreavam com aqueles/as que desejavam roubá-los. A ideia de menina delicada, recatada e submissa estava borrada pela potencialidade intempestiva de duas pastoras fortes, decididas e autônomas.

\section{Culturas Infantis e Relações Afetivas: o Olhar da Colonialidade ${ }^{6}$ para as Brincadeiras das Crianças Pequenininhas}

A forma com que concebemos as relações afetivas e sexuais entre as pessoas adultas prioriza a heterossexualidade, por meio de um dispositivo que a naturaliza e, ao mesmo tempo, tornando-a compulsória, expressando expectativas, demandas e obrigações sociais que derivam do pressuposto da heterossexualidade como natural e, portanto, fundamento da sociedade (MISKOLCI, 2009) 7 .

Um exemplo desse olhar pode ser percebido em uma conversa que o pesquisador Santiago teve com a docente Adeola, enquanto observavam as crianças brincando no ambiente externo da creche em que era realizada a pesquisa:

- Você já viu como a Farisa [menina branca pequenininha] e o Ife [menino branco pequenininho] brincam sempre juntos? Acho que eles são um casalzinho, vivem juntos sempre! Ele chega e já procura ela, é uma coisa impressionante. Ano passado ele batia muito nela, e acho que ela acabou gostando, porque hoje não desgruda. - Fragmento do diário de campo de Flávio Santiago, agosto de 2016 (SANTIAGO, 2019a, p. 79).

Durante a realização das entrevistas com Santiago, as docentes retomaram o tema de as duas crianças pequenininhas brincarem juntas, motivo sempre de um olhar normativo:

- Farisa e Ife são brancos, homem e mulher, então não há muita mistura de cor nos casais da sala. Informação verbal, Adeola, docente negra, entrevista concedida em 2016 a Flávio Santiago (SANTIAGO, 2019a, p. 80).

- A Farisa [menina branca pequenininha] eu sempre vejo com o Ife [menino branco pequenininho], mas aí eu não sei, as meninas dizem que essa afinidade vem do ano anterior e diz que eles estavam juntos no berçário e que o Ife batia muito nela e que ela sempre aceitou, né, receber as agressões. Eu vejo que eles brincam muito juntos, mas eu não sei se é porque foi reforçada essa relação entre eles. Informação verbal, Zarina, docente branca, entrevista concedida em 2016 a Flávio Santiago (SANTIAGO, 2019a, p. 82).

Nesse contexto, é importante pensarmos qual imagem se tem das meninas, pois, "[q]uando falamos do mito da fragilidade feminina, que justificou historicamente a proteção paternalista dos homens sobre as mulheres, de que mulheres estamos falando?” (CARNEIRO, 2011, p. 50). Teríamos o mesmo discurso das docentes se fossem duas crianças negras pequenininhas? Ou se a menina pequenininha fosse negra?

Em contrapartida, são acionadas, nesse contexto, as tramas do racismo, que reforçam os ideais de brancura e nação amalgamando relações afetivas entre pessoas brancas de sexo oposto. Já, para as pessoas negras, são interditadas essas mesmas experiências afetivas e, consequentemente, não compõem a imagem de formação de uma família normativa burguesa alicerçada na ideia do amor romântico (SANTIAGO, 2019a). Os traços fenotípicos e a estética são codificados como elementos que obstruem as preferências afetivas. 
Nesse contexto, as práticas racistas dividem e recortam relações, colaborando para o isolamento afetivo (PACHECO, 2008).

As relações matrimoniais no Brasil, como apontam as feministas negras, são marcadas diretamente pela hierarquização racial dos sujeitos; um exemplo ilustrativo desse processo é o quadro do pintor espanhol Modesto Brocos y Gómez, A Redenção de Cam (1895) (Fig. 1).

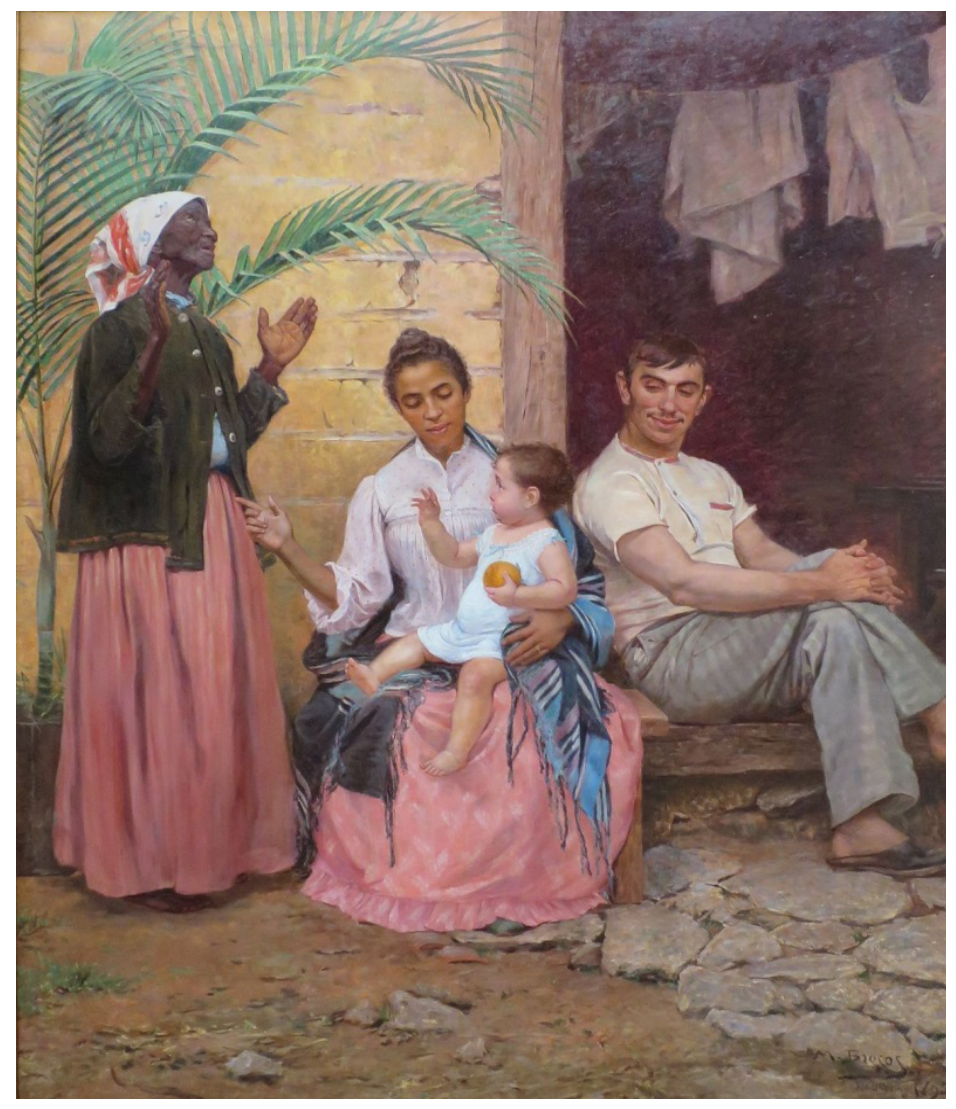

Fonte: Site Alma Petra.

Figura 1. Quadro de Modesto Brocos y Gómez (A Redenção de Cam, 1885).

O quadro representa uma constituição familiar ideal no contexto do branqueamento que rege as relações raciais no panorama brasileiro, trazendo três gerações marcadas pela gradação de cor. A obra foi pintada enquanto Modesto Brocos y Gómez, espanhol branco radicado no Brasil, lecionava na Escola Nacional de Belas Artes do Rio de Janeiro. O afeto entre pessoas negras não corresponde a um ideal presente no projeto racial do nosso país.

A obra de Modesto, como apontam Lotierzo e Schwarcz (2013), na medida em que retrata uma criança pequenininha e o pai como brancos do sexo masculino, constrói uma narrativa em que existe ruptura tanto de raça quanto de gênero.

Se é verdade que o movimento percorrido pela obra vai do negro ao branco, em conformidade com as projeções de uma vertente do pensamento racista do período, que apostava no branqueamento, é possível pensar que o quadro tem gênero definido: uma vez que o futuro racial da família em cena é um menino branco, o quadro procura exprimir, através da configuração raça/gênero, um certo olhar masculino de cumplicidade entre cavalheiros, assentado no impulso a confirmar a paternidade (branca) da criança (LOTIERZO; SCHWARCZ, p. 5). 
Assim, marcado por um projeto de branqueamento da nação, o afeto entre negros(as) se torna elemento de pânico, fato explicitado na pesquisa de campo quando um menino negro pequenininho e uma menina negra pequenininha passaram a estar mais vezes juntos, brincando sempre em conjunto no espaço externo. Diferentemente da reação sobre o par de crianças brancas, as docentes sempre repreendiam essa última relação, dizendo que era perigosa, que a Hasina não gostava que o Henrique estivesse junto a ela, ou então que

Henrique é muito carinhoso! Aí também tem essa questão de fazer carinho em excesso e falar da Hasina [menina negra pequenininha], ele fica muito grudado com a Hasina. O Henrique tem ficado ultimamente muito junto dela e ela está incomodada. Eu falei: "Henrique, não dá para fazer carinho se o outro não quer, você perguntou se ela quer? Não dá para ficar pondo a mão nela, então. Não dá. Perguntou se ela quer?" "Hasina, fala para ele, não", ela "não", ela é toda brava, a Hasina - informação verbal, Zarina, docente branca, entrevista concedida em 2016 (SANTIAGO, 2019a, p. 82).

Como aponta Santiago,

[...] Henrique realmente poderia estar incomodando Hasina, mas por que somente é destacado pela docente esse desconforto quanto ao excesso de carinho quando se trata de duas crianças negras pequenininhas? Em contrapartida a esse processo, como destacou Zarina, Ife, menino branco pequenininho, inicia a sua relação de proximidade com uma colega com a agressividade e não se tem a mesma percepção quanto ao caráter agressivo da relação (2019a, p. 83).

A masculinidade dos brancos é naturalmente concebida de modo agressivo, e a agressividade faz parte do leque de ações determinadas aos homens e meninos brancos para a conquista de seus afetos, sua propriedade. Isso reforça o imaginário de virilidade associado a ser masculino e branco, diferentemente da masculinidade negra, que está na chave da feminilidade, ligada àquilo que não é humano, no âmbito do selvagem; aquilo que deve ser civilizado, pois não é o padrão determinado pela colonialidade nem representa a figura de homem. Nesse contexto, o racismo interdita a vida, estruturando uma morte social ${ }^{8}$, dilacerada para além do próprio sentimento de luto. "[N]o racismo, a negação é usada para manter a legitimar estruturas violentas de exclusão [...] o sujeito negro torna-se então aquilo a que o sujeito branco não que ser relacionado" (KILOMBA, 2019, p. 34).

O afeto tornou-se um privilégio nas relações interpessoais, estando marcado pela desigualdade: 0 amor, o carinho, o princípio de partilha, a preocupação, os cuidado mútuos e a alteridade são estabelecidos com base nas estruturas hierárquicas fundamentadas pelo racismo, o sexismo e os privilégios de classe presentes nas sociedades capitalistas, configurando produtos da segmentação das relações de poder (SANTIAGO, 2019a). As relações de afeto, como pontua Silva (2017), muitas vezes reproduzem o racismo, ecoando a ideia de que a humanidade não pertencente a todos; é necessário possuir determinadas características fenotípicas para ter o direito a acessar determinadas práticas sociais, entre as quais a alteridade, o carinho etc. No texto "Vivendo de Amor", hooks (2010) destaca a violência que o processo de escravização, exemplo máximo de desumanização das pessoas, causou nas relações afetivas, deixando marcas históricas que reverberam até a contemporaneidade.

Vale destacar que o processo de desumanização não se inicia no interior das creches e pré-escolas; as práticas sociais ali estabelecidas reverberam uma estrutura posta na sociedade capitalista. O racismo é estruturante dos padrões, estando inserido em todas os espaços sociais (GOMES; LARBONE, 2018). As vidas negras no interior desse processo não são reconhecidas como merecedoras de humanidade, como mostra o genocídio das pessoas negras ou a morte de inúmeras crianças por balas perdidas que sempre encontram os 
corpos negros 9 . Assim, situações racistas, que desumanizam as crianças negras pequenininhas na educação infantil, são reflexo desse contexto macro que estrutura a sociedade, pautada em hierarquias que legitimam privilégios raciais.

O movimento feminista negro tem discutido e lutado pela desconstrução do processo de desumanização. Nesse cenário racista, os afetos, a morte social ou física, o sonho de um príncipe encantado ou mesmo o casamento idealizado no inconsciente patriarcal ao longo dos séculos não fazem parte da realidade da população negra. Paralelamente a esse processo, constrói-se a ideia de que as mulheres negras são mais fortes. Contudo, como aponta Ribeiro,

[...] o fato de ela ter de ser forte, guerreira, é uma imposição do Estado, que é omisso. Eu não gosto de colocar a mulher negra inerentemente forte porque acho que é desumano. Eu também tenho direito à fragilidade. Eu sou uma pessoa como outra qualquer, tem dia que estou triste, que eu me sinto fraca. Nós somos fortes, sim, mas querer naturalizar isso é escamotear a omissão do Estado. A gente tem que ser forte porque as oportunidades não são iguais, porque a realidade é muito violenta. A mulher negra também tem o direito de ser frágil e de não ter que carregar o mundo nas costas (RIBEIRO apud OLIVEIRA, 2016).

Considerando esse universo de pontos de vista, Santiago se inquieta com a fala da docente e levanta alguns questionamentos: "como as meninas pequenininhas, negras e brancas, e os meninos pequenininhos, negros e brancos, brincam quando estão juntos(as)?” (2019a, p. 82). Com o intuito de tentar olhar para essas relações de modo menos adultocêntrico, o pesquisador se aproxima das brincadeiras construídas entre "casais" e faz parte delas. Nesse momento, tem uma surpresa, como podemos observar no diálogo a seguir:

- Farisa [menina branca pequenininha], posso brincar com vocês?

- Pode, tio!

- E do que vocês estão brincando?

- Eu estou brincando de mandar no Ife!

- Como assim, Farisa?

- Eu sou a mãe dele, a tia dele, a professora dele! Eu mando nele!

- Nossa, e como brinca?

- SENTA ALI, TIO, E FICA QUIETO! Fragmento do diário de campo, agosto de 2016 (SANTIAGO, 2019a, p. 83, grifo dos autores).

A brincadeira das crianças pequenininhas não necessariamente estava relacionada aos aspectos amorosos, como as(os) adultas(os) imaginavam. As "crianças, desde bem pequenas, pensam organizando o pensamento de forma sofisticada e complexa” (MELLO; BARBOSA; FARIA, 2011, p. ix), construindo e reconstruindo as relações sociais. "Crianças produzem e criam seus próprios mundos coletivos num sentido genérico. Embora sejam afetadas pelo mundo adulto (que também afetam), as culturas de pares das crianças têm sua própria autonomia" (CORSARO, 2011, p. 275).

Essa forma de conceituação possibilita a ampliação do nosso olhar diante das crianças, especificando as múltiplas relações que estabelecem com o mundo, entre as quais está seu pertencimento 
racial, de gênero e de classe social, explicitando que meninas e meninos são criaturas e criadores(as) da história e da cultura. Meninas e meninos, negros(as) e brancos(as), no convívio com as diferenças, são capazes de estabelecer múltiplas relações, construindo saberes, reproduzindo e criando significados - demonstrando, assim, as oportunidades de poder ser criança e vivendo a especificidade infantil, criando e recriando as culturas infantis (FARIA, 2005).

O racismo tenta construir a ideia imperativa de "morte" das diferenças étnico-raciais, contudo, as crianças pequenininhas negras gritam "vida". O mesmo poder que achata as singularidades recebe violentamente uma força de resistência que o impede de apagar e construir um espaço homogêneo e linear. Os choros, as rebeldias infantis são armas de uma guerrilha a favor da vida; transmutações concretas de resistência pela não pasteurização dos sujeitos (SANTIAGO, 2015, p. 143).

Assim, retomamos o episódio descrito anteriormente e perguntamos: a quem serve a percepção das crianças pequenininhas como namoradas? A quem serve a legitimação de algumas formas de parceria entre as crianças pequenininhas e a interdição dessas relações para outras? Para ajudar a pensar essa questão, retomamos os escritos de Rosemberg (1976) a respeito do adultocentrismo. Segundo a saudosa pesquisadora feminista, uma das características dessa forma de colonialismo é a invisibilidade do protagonismo das crianças: "na sociedade centrada no adulto, a criança não é. Ela é um vir a ser. Sua individualidade mesma deixa de existir. Ela é potencialmente a promessa" (ROSEMBERG, 1976, p. 1467).

$\mathrm{O}$ "destino das crianças é a espera - paciente, até se tornarem adultas, para terem sua construtividade reconhecida, o que dizer sobre assuntos sociais, para ser parte da coletividade de cidadãos" (QVORTRUP, 2014 , p. 32). E às meninas pequenininhas e aos meninos pequenininhos, o que cabe fazer durante todo o período da infância? Esperar? Obedecer? Só lhes resta aprender a amar apenas pessoas de determinado fenótipo, do sexo oposto, de modo a estabelecer relações segundo as regras normativas que os(as) adultos(as) desejam?

\section{Considerações Finais}

O olhar das feministas negras contribui para percebermos as culturas infantis inseridas em um contexto mais amplo, no qual os marcadores sociais, como gênero, classe social e raça, estão diretamente correlacionados. As feministas negras também destacam que as generalizações que "não levem em consideração as estruturas interligadas de posicionamento e opressão de um grupo dentro de uma economia são simplesmente abrangentes" (COLLINS, 2016, p. 120) e abstratas, pois não pontuam as especificidades da desigualdade dentro de um contexto macroestruturante.

As crianças negras, desde os primeiros dias de vida, já convivem com o racismo. São desumanizadas, estão sendo mortas - uma morte social, em que se retira o direito de participarem das brincadeiras -, ou já são tachadas como as mais bagunceiras, agressivas; 'o racismo tenta construir a ideia imperativa de 'morte' das diferenças étnico-raciais, contudo, as crianças negras gritam 'vida”' (SANTIAGO, 2015, p. 143). Pensar as produções das crianças pequenininhas desassociadas dos elementos sociais que estruturam a nossa sociedade a partir dessa perspectiva torna-se um problema, pois isso não corresponde à realidade, transmitindo somente uma ideia parcial daquilo que está sendo estabelecido nas relações sociais. As pesquisas relativas às culturas infantis, ao serem inquietadas com os questionamentos do Feminismo Negro, ganham novas dimensões epistêmicas, trazendo para o campo de estudo elementos que, à primeira vista, com um olhar canônico eurocêntrico e branco, podem parecer superficiais ou irrelevantes, mas que, em uma visão não branca, 
ganham contornos em que se pode compreender práticas e hierarquizações sociais presentes na sociedade capitalista. Os movimentos sociais, como destaca Gomes, são "os produtores e articuladores dos saberes construídos pelos grupos não hegemônicos e contra-hegemônicos da nossa sociedade” (2017, p. 16), o que traz para o debate inquietações de extrema relevância para se pensar os aportes teóricos e metodológicos que fundamentam nossas pesquisas.

Apesar de as feministas negras, muitas vezes, praticarem a intersecção gênero, raça e classe social sem tocarem na temática das crianças pequenininhas e das culturas infantis, o olhar por elas construído possibilita a pesquisadores e pesquisadoras das infâncias, a criancistas e a criançólogos(as) questionarmos e desnaturalizarmos algumas visões ainda eurocêntricas e abstratas, que estão enraizadas em nossa própria área de estudo e pesquisa, favorecendo, assim, a descolonização do nosso pensamento. Outro elemento de fundamental destaque é o convite que as feministas negras nos fazem para olhar um pouco mais de perto as relações sociais, já que nem tudo está baseado em um único sistema macroestruturante. Em geral, a unidade na luta contra a desigualdade "não depende apenas de nossa capacidade de superar as desigualdades geradas pela histórica hegemonia masculina, mas exige, também, a superação de ideologias complementares desse sistema de opressão, como é o caso do racismo" (CARNEIRO, 2011). Assim, a pesquisadores e pesquisadoras da pequena infância fica a inquietação de também olharmos as crianças de modo mais próximo, conhecermos a microestrutura de produção das culturas infantis e suas correlações com a sociedade. Como educar as crianças para o feminismo, a partir de uma perspectiva interseccional, desde a creche?

Outro aspecto que vale retomarmos nesse momento é pensar as culturas infantis com um olhar carregado pelo adultocentrismo e também pelo racismo e pelo sexismo que perpassam as nossas relações sociais; o protagonismo infantil torna-se, a partir desses óculos coloniais, mera reprodução da sociedade, não existindo algo novo ou mesmo autoral. As crianças também subvertem a lógica dominante, criando e recriando a vida dentro das condições dadas. Não são cidadãos de pouca idade, inertes. Por meio do brincar e de um modo diverso dos adultos, novas formas de organizações e de relações sociais são pautadas nas percepções raciais e de gênero.

Por fim, é fundamental destacarmos que as feministas negras construíram uma revolução epistêmica na forma de se olhar para as relações de opressão no mundo, "inaugurando" o que conhecemos como interseccionalidade. Aliados a essa nova forma de percepção das relações sociais, temos realizado nossas pesquisas e convidamos os pesquisadores e as pesquisadoras a olhar o protagonismo da infância em suas relações para com o mundo, de modo a não valorizar somente uma percepção adultocêntrica da infância, mas também outras formas de perceber a vida a partir das perspectivas das crianças. As crianças agradecem!!!

\section{Contribuição dos Autores}

Problematização e Conceituação: Santiago F; Faria ALG; Metodologia: Santiago F; Faria ALG; Análise: Santiago F; Faria, ALG; Redação: Santiago F; Faria ALG.

\section{Notas}

1. É importante destacar que a pesquisa contou com a aprovação do Comitê de Ética em Pesquisa, sendo emitido, no dia 2 de fevereiro de 2016, Parecer n. 50873015.0.0000.5404. Os nomes das docentes e das crianças pequenininhas também foram substituídos por pseudônimos, a fim de preservar o anonimato e a privacidade. 
2. Vale destacar que não existe um consenso em relação ao uso dos termos "crianças pequenininhas" e "bebês"; os seus usos estão diretamente ligados às perspectivas teórico-metodológicas que os(as) pesquisadores(as) mobilizam na construção dos seus estudos e pesquisas. A respeito disso, destacamos a discussão realizada por Gabriela Guarnieri de Campos Tebet e Anete Abramowicz, no artigo "Estudos de bebês: linhas e perspectivas de um campo em construção" (2018), no qual as autoras articulam suas argumentações a partir de um referencial pós-estruturalista.

3. "A ciência ocidental apresenta uma postura adultocêntrica, em que aquele que é considerado o mais forte em sociedades competitivas olha para a infância como se procurasse um outro adulto, o adulto que a criança será. A biologização e naturalização da criança e do bebê, com os padrões adultos e de maturidade permeando a compreensão do desenvolvimento, retiram da infância a sua historicidade e seu potencial transformador" (ROSEMBERG, 1976, p. 1467-1468).

4. Para maiores detalhes ler Barbosa (2014) e Muller (2006).

5. Meninas pequenininhas que, posteriormente, começaram a brincar com os meninos pequenininhos.

6. “A 'colonialidade' é um conceito que foi introduzido pelo sociólogo peruano Anibal Quijano, no final dos anos 1980 e no início dos anos 1990, que eu elaborei em Histórias locais/projetos globais e em outras publicações posteriores. Desde então, a colonialidade foi concebida e explorada por mim como o lado mais escuro da modernidade. Quijano deu um novo sentido ao legado do termo colonialismo, particularmente como foi conceituado durante a Guerra Fria junto com o conceito de 'descolonização' (e as lutas pela libertação na África e na Ásia). A colonialidade nomeia a lógica subjacente da fundação e do desdobramento da civilização ocidental desde o Renascimento até hoje, da qual colonialismos históricos têm sido uma dimensão constituinte, embora minimizada" (MIGNOLO, 2017, p. 2).

7. Para maior aprofundamento a respeito da temática, ver Barreiro (2019).

8. Para maiores detalhes, ler Mbembe (2016).

9. Para maiores detalhes, ler Almeida (2014) e Marques Junior (2020).

\section{Referências}

AKOTIRENE, C. O que é interseccionalidade? Belo Horizonte: Letramento/Justificando, 2018.

ALMEIDA, M. S. et al. Desumanização da população negra: genocídio como princípio tácito do capitalismo. Revista em Pauta, Rio de Janeiro, v. 12, n. 34, p. 131-154, 28 dez. 2014. https://doi.org/10.12957/rep.2014.15086

BAIRROS, L. (1990). A mulher negra e o feminismo. In: COSTA, A. A.; SARDENBERG, C. M. B. (orgs). Relatório do Seminário Nacional: o feminismo no Brasil - reflexões teóricas e perspectivas. 2. ed. Salvador: NEIM/UFBA, 2008. p. 139-145.

BARBOSA, M. C. S. Culturas infantis: contribuições e reflexões. Revista Diálogo Educacional, Curitiba, v. 14, n. 43, p. 645-667, jul. 2014. https:// doi.org/10.7213/dialogo.educ.14.043.ds01

BARREIRO, A. Gênero e Educação Infantil: política das identidades. São Carlos: Pedro \& João Editores, 2019. BENJAMIM, W. Reflexões: a criança, o brinquedo, a educação. São Paulo: Summus, 1984.

BRAH, A. Diferença, diversidade, diferenciação. Cadernos Pagu, Campinas, n. 26, p. 329-376, 2006. https:// doi.org/10.1590/S0104-83332006000100014 
CARNEIRO, S. Enegrecer o feminismo: a situação da mulher negra na américa latina a partir de uma perspectiva de gênero. A situação da mulher negra na América Latina a partir de uma perspectiva de gênero. Portal Geledés, 2011. Disponível em: https://www.geledes.org.br/enegrecer-o-feminismo-situacao-damulher-negra-na-america-latina-partir-de-uma-perspectiva-de-genero/. Acesso em: 5 jun. 2020.

COHN, C. Antropologia da criança. Rio de Janeiro: Zahar, 2005.

COLLINS, P. H. The social construction of black feminist thought. In: MALSON, M. R. et al. Black women in America: social science perspectives. Chicago: The University of Chicago Press, 1990. p. 297-325.

COLLINS, P. H. Aprendendo com a outsider within: a significação sociológica do pensamento feminista negro. Sociedade Estado, Brasília, DF, v. 31, n. 1, p. 99-127, 2016, https://doi.org/10.1590/S0102-69922016000100006 CORSARO, W. A. Sociologia da infância. 2. ed. Porto Alegre: Artmed, 2011.

CRENSHAW, K. Documento para o encontro de especialistas em aspectos da discriminação racial relativos ao gênero. Revista Estudos Feministas. Florianópolis, v. 10, n. 1, p. 171-188, 2002. https://doi.org/10.1590/ S0104-026X2002000100011

FACCHINI, R. Feminismos e estudos sobre mulheres e gênero no Brasil: um olhar a partir das articulações presentes na luta por creches. In: TELES, M. A.; SANTIAGO, F.; FARIA, A. L. (orgs.). Por que a creche é uma luta das mulheres? Inquietações feministas já demonstram que as crianças pequenas são de responsabilidade de toda a sociedade! São Carlos: Pedro \& João Editores, 2018. p. 35-64.

FARIA, A. L. G. Políticas de regulação, pesquisa e pedagogia na educação infantil, primeira etapa da educação básica. Educação \& Sociedade, Campinas, v. 26, n. 92, p. 1013-1038, out. 2005. https://doi.org/10.1590/ S0101-73302005000300014

FERNANDES, F. As trocinhas do Bom Retiro: folclore e mudança social na cidade de São Paulo. São Paulo: Martins Fontes, 2004. p. 203-315.

GOBBI, M. A. Lápis vermelho é de mulherzinha: vinte anos depois... In: FINCO, D.; GOBBI, M. A.; FARIA, A. L. G. (orgs.). Creche e feminismo: desafios atuais para uma educação descolonizadora. Campinas: Edições Leitura Crítica/Fundação Carlos Chagas/Associação de Leitura do Brasil, 2015. p. 137-163.

GOMES, N. L. O movimento negro educador: saberes construídos nas lutas por emancipação. Petrópolis: Vozes, 2017.

GOMES, N. L. Raça e educação infantil: à procura de justiça. Revista e-Curriculum, São Paulo, v. 17, n. 3, p. 1015-1044, set. 2019. https://doi.org/10.23925/1809-3876.2019v17i3p1015-1044

GOMES, N. L.; LABORNE, A. A. P. Pedagogia da crueldade: racismo e extermínio da juventude negra. Educação em Revista, Belo Horizonte, v. 34, e197406, 2018. https://doi.org/10.1590/0102-4698197406

GONZALEZ, L. Racismo e sexismo na cultura brasileira. Revista Ciências Sociais Hoje, Brasília, n. 2, p. 223-244, 1983.

hooks, B. Vivendo de amor. Portal Geledés, 9 mar. 2010. Disponível em: https://www.geledes.org.br/vivendode-amor/. Acesso em: 22 dez. 2015.

hooks, B. O feminismo é para todo mundo: políticas arrebatadoras. Rio de Janeiro: Editora Rosa dos Tempos, 2018. 
KILOMBA. G. Memórias da plantação: episódios de racismo cotidiano. Rio de Janeiro: Cobogó, 2019.

KYRILLOS, G. M. Uma análise crítica sobre os antecedentes da interseccionalidade. Revista de Estudos Feministas, Florianópolis, v. 28, n. 1, p. 1-12, 2020. https://doi.org/10.1590/1806-9584-2020v28n156509

LOTIERZO, T. H. P.; SCHWARCZ, L. K. M. Raça, gênero e projeto branqueador: “a redenção de Cam”, de Modesto Brocos. Artelogie, Paris, n. 5, out. 2013. Disponível em: http://cral.in2p3.fr/artelogie/spip. php?article254. Acesso em: 24 out. 2018.

MACEDO, E. E. Crianças pequenininhas e a luta de classes. 2016. 135 f. Tese (Doutorado em Educação) Faculdade de Educação, Universidade Estadual de Campinas, Campinas, 2016.

MARQUES JUNIOR, J. S. O “equívoco" como morte negra, ou como "naturalizar" balas racializadas. Revista Katálysis, Florianópolis, v. 23, n. 2, p. 366-374, maio 2020. https://doi.org/10.1590/1982-02592020v23n2p366

MBEMBE, A. Necropolítica. Arte e ensaios, Rio de Janeiro, v. 2, n. 32, p. 122-151, dez. 2016.

MELLINO, M.. Notas sobre o método de Stuart Hall, Althusser, Gramsci e a questão da raça. Mouro - Revista Marxista, [S. 1.], ano 10, n. 13, p. 87-124, jan. 2019.

MELLO, S.; BARBOSA, M. C.; FARIA, A. L. G. Prefácio. In: STAMBAK, M. et al. Os bebês entre eles: descobrir, brincar, inventar juntos. Campinas: Autores Associados, 2011. p. ix-xii.

MIGNOLO, W. D. Colonialidade: o lado mais escuro da modernidade. Revista Brasileira de Ciências Sociais, São Paulo, v. 32, n. 94, 2017. https://doi.org/10.17666/329402/2017

MIGUEL, A. Exercícios descolonizadores a título de prefácio: isto não é um prefácio e nem um título. In: FARIA, A. L. G. et al. Infância e Pós-colonialismo: pesquisas em busca de pedagogias descolonizadoras. Campinas: Leitura Crítica/ALB, 2015. p. 25-55.

MISKOLCI, R. A Teoria Queer e a Sociologia: o desafio de uma analítica da normalização. Sociologias, Porto Alegre, v. 11, n. 21, p. 150-182, jan./jun. 2009. https://doi.org/10.1590/S1517-45222009000100008

MOREIRA, N. R. A organização das feministas negras no Brasil. Vitória da Conquista: Edições UESB, 2011.

MOREIRA, N. R. Feminismo negro brasileiro: igualdade, diferença e representação. In: ENCONTRO DA ANPOCS, 31., 2017, Caxambu. Anais... Caxambu, 2017. p. 1-22. Disponível em: http://www.anpocs.com/ index.php/papers-31-encontro/st-7/st18-5/2961-nubiamoreira-feminismo/file. Acesso em: 20 maio 2020.

MULLER, F. Infâncias nas vozes das crianças: culturas infantis, trabalho e resistência. Educação \& Sociedade, Campinas, v. 27, n. 95, p. 553-573, maio/ago. 2006. https://doi.org/10.1590/S0101-73302006000200012

OLIVEIRA, A. F. Djamila Ribeiro, a voz da consciência negra feminina no Brasil. Vice, 2016. Disponível em: https://www.vice.com/pt_br/article/bmgkvd/entrevista-djamila-ribeiro2016. Acesso em: 12 set. 2019.

OLIVEIRA, M. R. G. O que não tem nome não existe! Feminismo negro e o percurso histórico do conceito de interseccionalidade. In: OLIVEIRA, L. Z.; CUNHA, J. M.; KIRCHHOFF, R. S. Educação e interseccionalidades. Curitiba: NEAB-UFPR, 2018. p. 19-48.

PACHECO, A. C. L. "Branca para casar, mulata para f... e negra para trabalhar": escolhas afetivas e significados de solidão entre mulheres negras em Salvador, Bahia. 2008. 317 f. Tese (Doutorado em Ciências 
Sociais) - Instituto de Filosofia e Ciências Humanas, Universidade Estadual de Campinas, Campinas, 2008.

PEREIRA, A. O. Amigues: um estudo interseccional das práticas de amizade entre as crianças pequenas na educação infantil. 2020. 146 f. Dissertação (Mestrado em Educação) - Faculdade de Educação, Universidade Estadual de Campinas, Campinas, 2020.

PRADO, P. D. Educação e cultura infantil em creche: um estudo sobre as brincadeiras de crianças pequenininhas em um CEMEI de Campinas/SP. 1998. 139 f. Dissertação (Mestrado em Educação) - Faculdade de Educação, Universidade Estadual de Campinas, Campinas. 1998.

PRADO, P. D. As crianças pequenininhas produzem cultura? Considerações sobre educação e cultura infantil em creche. Pro-Posições, Campinas, v. 10, n. 1, p. 110-118, 1999.

QVORTRUP, J. Visibilidades das crianças e da infância. Linhas Críticas, Brasília, v. 20, n. 41, p. 23-42, jan./ abr. 2014. https://doi.org/10.26512/lc.v20i41.4250

RIBEIRO, D. O que é lugar de fala? Belo Horizonte: Letramento/Justificando, 2017.

RIBEIRO, D. Feminismo negro como perspectiva emancipatória. In: TELES, M. A. A.; SANTIAGO, F.; FARIA, A. L. G. (orgs.). Por que a creche é uma luta das mulheres? Inquietações feministas já demonstram que as crianças pequenas são de responsabilidade de toda a sociedade! São Carlos: Pedro \& João, 2018. p. 65-91.

ROSEMBERG, F. Educação para quem? Ciência e Cultura, São Paulo, v. 28, n. 12, p. 1466-1471, 1976.

SANTIAGO, F. Gritos sem palavras: resistências das crianças pequenininhas negras frente ao racismo. Educação em Revista, Belo Horizonte, v. 31, n. 2, p. 129-153, jun. 2015. https://doi.org/10.1590/0102-4698132765

SANTIAGO, F. Eu quero ser o sol! (Re)interpretações das intersecções entre as relações raciais e de gênero nas culturas infantis entre crianças de 0 à 3 anos em creche. 2019. 111 f. Tese (Doutorado em Educação) Faculdade de Educação, Universidade Estadual de Campinas, Campinas, 2019a.

SANTIAGO, F. Branquitude e creche: inquietações de um pesquisador branco. Educar em Revista, Curitiba, v. 35, n. 76, p. 305-330, ago. 2019b. https://doi.org/10.1590/0104-4060.66099

SANTIAGO, F. "Não é nenê, ela é preta”: educação infantil e pensamento interseccional. Educação em Revista, Belo Horizonte, v. 36, e220090, 2020. https://doi.org/10.1590/0102-4698220090

SAYÃO, D. T. Pequenos homens, pequenas mulheres? Meninos, meninas? Algumas questões para pensar as relações entre gênero e infância. Pro-Posições, Campinas, v. 14, n. 3, p. 67-87, mar. 2016. Disponível em: https://periodicos.sbu.unicamp.br/ojs/index.php/proposic/article/view/8643862/11339. Acesso em: 15 fev. 2019.

SILVA, P. B. G. Chegou a hora de darmos a luz a nós mesmas: Situando-nos enquanto mulheres e negras. Cadernos CEDES, Campinas, v. 19, n. 45, p. 7-23, jul. 1998. https:// doi.org/10.1590/S0101-32621998000200002

SILVA, P. B. G. O sentimento, a compreensão de que se pertence à humanidade começa desde sempre. In: SANTOS, S. E. et al. Pedagogias descolonizadoras e infâncias: por uma educação emancipadora desde o nascimento. Maceió: EDUFAL, 2017. p. 71- 86.

SOCI, D. Da femmina e da maschio. Un progetto sull'identità e le differenze di genere nella scuola dell'infanzia. Riviste Erickson, Trento, v. 13, n. 3, ott. 2015. Disponível em: http://rivistedigitali.erickson.it/ 
educazione-interculturale/archivio/vol-13-n-3/article/da-femmina-e-da-maschio-un-progetto-sullidentitae-le-differenze-di-genere-nella-scuola-dellinfanzia/. Acesso em: 17 fev. 2019.

TEBET, G. C.; ABRAMOWICZ, A. Estudos de bebês: linhas e perspectivas de um campo em construção. ETD - Educação Temática Digital, Campinas, v. 20, n. 4, p. 924-946, 14 out. 2018. https://doi.org/10.20396/ etd.v20i4.8649692

VELHO, G. Observando o familiar. In: NUNES, E. O. A aventura sociológica. Rio de Janeiro: Jorge Zahar, 1978. p. 36-46.

WESCHENFELDER, V. I.; FABRIS, E.T. H. Tornar-se mulher negra: escrita de si em um espaço interseccional. Revista de Estudos Feministas, Florianópolis, v. 27, n. 3, p. 1-15, 2019. https://doi. org/10.1590/1806-9584-2019v27n354025

\section{Sobre os Autores}

Flávio Santiago realiza estágio de pós-doutoramento na Universidade de São Paulo (USP) junto ao Departamento de Metodologia do Ensino e Educação Comparada da Faculdade de Educação; é doutor em Educação pela Universidade Estadual de Campinas (UNICAMP, 2019). Atualmente também é tutor a distância do Instituto Federal de Pernambuco, no curso de pós-graduação lato sensu em Docência para Educação Profissional e Tecnológica. Pesquisa sobre: pedagogia da infância, relações raciais e de gênero, migrações internacionais e educação das relações étnico-raciais na educação básica.

Ana Lúcia Goulart de Faria é paulistana desvairada, criancista e criançóloga, antifascista, marxista e feminista. É pedagoga, professora permanente aposentada, colaboradora da Faculdade de Educação da Universidade Estadual de Campinas (UNICAMP). Coordenadora da linha Culturas Infantis do Grupo de Estudos e Pesquisa em Educação e Diferenciação Sociocultural (GEPEDISC). Membro do grupo gestor do Fórum Paulista de Educação Infantil. Ex-membro do Conselho Municipal de Educação de Campinas. Ex-membro do colegiado docente de doutorado da Faculdade de Ciências da Formação da Università Degli Studi Milano Bicocca, e pesquisadora da mesma desde 2010 quando realizado pós doc com bolsa CAPES. .

Recebido: 22 jul. 2020

Aceito: 26 out. 2020 